\title{
Review of the grassland leafhopper genus Exitianus Ball (Hemiptera, Cicadellidae, Deltocephalinae, Chiasmini) from China
}

\author{
Yani Duan ${ }^{1,2}$, Yalin Zhang ${ }^{2}$ \\ I School of Plant Protection, Anhui Agricultural University, Hefei, Anhui Province 230036, China 2 Key La- \\ boratory of Plant Protection Resources and Pest Management of Ministry of Education, Entomological Museum, \\ Northwest A \& F University, Yangling, Shaanxi Province 712100, China
}

Corresponding author: Yalin Zhang (yalinzh@nwsuaf.edu.cn)

Academic editor: Mick Webb | Received 15 April 2013 | Accepted 1 August 2013 | Published 20 September 2013

Citation: Duan Y, Zhang Y (2013) Review of the grassland leafhopper genus Exitianus Ball (Hemiptera, Cicadellidae, Deltocephalinae, Chiasmini) from China. ZooKeys 333: 31-43. doi: 10.3897/zookeys.333.5324

\begin{abstract}
The two Chinese species of the leafhopper genus Exitianus Ball (Hemiptera: Cicadellidae: Deltocephalinae: Chiasmini) (E. indicus (Distant) and E. nanus (Distant)) are reviewed. Descriptions of the species and a key for their separation are provided. E. fulvinervis $\mathrm{Li} \& \mathrm{He}$ is considered a junior synonym of $E$. nanus syn. n.
\end{abstract}

\section{Keywords}

Hemiptera, Auchenorrhyncha, morphology, taxonomy

\section{Introduction}

Among the most widespread and often abundant tropical and temperate species of grassland leafhoppers are the moderately large tawny forms comprising the genus Exitianus Ball. It contains 43 species of which 6 species occur in Asia. Members of the genus are most readily distinguished by usually having a transverse dark band on the vertex (Plate II: A-E), males with a small number of apical stout setae on the pygofer (Figs 1A-D) and the female with a relatively long ovipositor extending conspicuously beyond the last dorsal segment (Plate I: D). These characters are shared only by the presumably sister 
genus Nephotettix Matsumura, but which differs in having the crown sharply ridged where it meets the face, and being opaque green with various black markings.

This study reviews for the first time the species of Exitianus from China. From using the revision of Ross (1968) we identify two species (E. indicus (Distant) and E. nanus (Distant)) but have found and figured further variation in the male genitalia to that given by Ross for the two species. With respect to E. nanus these findings allow us to place E. fulvinervis $\mathrm{Li} \& \mathrm{He}$, from China, as a junior synonym. As our work includes the study of numerous specimens we conclude that the remaining three species recorded from China, i.e., E. capicola (Stål) by Matsumura (1914: 186), E. coronatus (Distant) by Li et al. (2011: 69, fig. 57) and E. fusconervosus (de Motschulsky) by Kuoh (1966: 143, fig. 133) are probably misidentifications.

\section{Material examined}

Material examined is deposited in the Entomological Museum of Northwest A \& F University (NWAFU) and the Institute of Zoology, the Chinese Academy of Sciences (IZCAS). Morphological terminology follows Oman (1949) and Zhang (1990).

\section{Taxonomy}

\section{Exitianus Ball}

http://species-id.net/wiki/Exitianus

Exitianus Ball, 1929: 5. Type species: Cicadula obscurinervis Stål.

Mimodrylix Zachvatkin, 1935: 108. Type species: Athysanus capicola Stål. Synonymized by Evans 1947: 235.

Exitianus; Ross 1968: 1-30 [Review].

Exitianus; Oman, Knight and Nielson 1990: 213 [Listed; Athysanini].

Exitianus; Fang et al. 1993 [Phylogeny, mitochondrial sequences].

Exitianus; Emeljanov 1999: 547 [To Doraturini].

Exitianus; Dmitriev 2003: 677 [Immatures].

Exitianus; Zahnizer and Dietrich 2013: 56 [To Chiasmini].

Remarks. An adequate description of this genus is given by Ross (1968). See introduction for the main distinguishing features. The two species from China can be separated by the following key.

\section{Key to species of Exitianus Ball from China}

$1 \quad$ Vertex usually with transverse arcuate brown band interrupted medially (Plate I: A-B). Scutellum with dark brown basal triangles (Plate I: A-B). 
Male pygofer side with 2-6 apical brown or black macrosetae (Figs 1A-D). Aedeagal shaft slightly laterally compressed with small gonoduct (Fig. 2C); without processes (Figs 2B-C). Female VIIth sternite with posterior margin tri-lobed (Plate I: D)

E. nanus

- $\quad$ Vertex usually with transverse arcuate brown band complete (Plate II: A-E). Scutellum with faint brown basal triangles (Plate II: A-E). Male pygofer side with 2-3 apical brown or black macrosetae (Figs 3-4). Aedeagal shaft strongly laterally compressed, gonopore large with rim forming concave margin in lateral view; with pair of small dorsobasal processes (Figs 5G, 6). Female VIIth sternite with a shallow notch in mid-line (Plate II: G).

E. indicus

\section{Exitianus nanus (Distant)}

http://species-id.net/wiki/Exitianus_nanus

Plate I, Figures 1-2

Athysanus nanus Distant, 1908: 345.

Athysanus insularis; Distant 1909: 47, pl. 4, figs 10, 10a. Synonymized by Ross 1968: 7. Athysanus fasciolatus; Melichar 1911: 107. Synonymized by Linnavuori 1975: 626. Athysanus simillimus; Matsumura 1914: 185. Synonymized by Ross 1968: 7. Athysanus vulnerans; Bergevin 1925: 42, figs 5-9. Synonymized by Ross 1968: 7. Limotettix albipennis; Haupt 1927: 25, pl. II, figs 20a-c. Synonymized by Dlabola 1963: 325.

Limotettix unifasciata; Haupt 1930: 159, fig. 9. Synonymized by Dlabola 1963: 325. Athysanus digressus; Van Duzee 1933: 32. Synonymized by Linnavuori and DeLong 1978: 237.

Exitianus nanus; Ross 1968: 7, figs 1-3, 15-18, 76.

Exitianus karachiensis; Ahmed 1986: 59, fig. 5. Synonymized by Khatri and Webb 2010: 10.

Exitianus peshawarensis; Ahmed and Rao 1986: 76-77, fig. 1. Synonymized by Khatri and Webb 2010: 10.

Exitianus minor; Ahmed, Qadeer and Malik 1988: 12, fig. 2. Synonymized by Khatri and Webb 2010: 10.

Exitianus fulvinervis; Li and He 1993: 27; Li et al. 2011: 68, fig. 55. syn. n.

Description. Length. Male: $3.0-4.1 \mathrm{~mm}$; female: $3.9-5.2 \mathrm{~mm}$.

Yellow-brown with variable brown markings on vertex comprising spots on anterior margin and a more posterior arcuate band interrupted medially (Plate I: A-B); frontoclypeus with faint brown lateral arcs (Plate I: C). Pronotum usually with some dark infuscation (Plate I: A-B). Scutellum with dark brown basal triangles (Plate I: A-B).

Crown width about $3 \times$ length (Plate I: A-B).

Male genitalia. Pygofer side usually with 2-6 apical brown or black macrosetae (Figs 1A-D). Style preapical lobe broadly triangular, apophysis evenly tapered to apex 

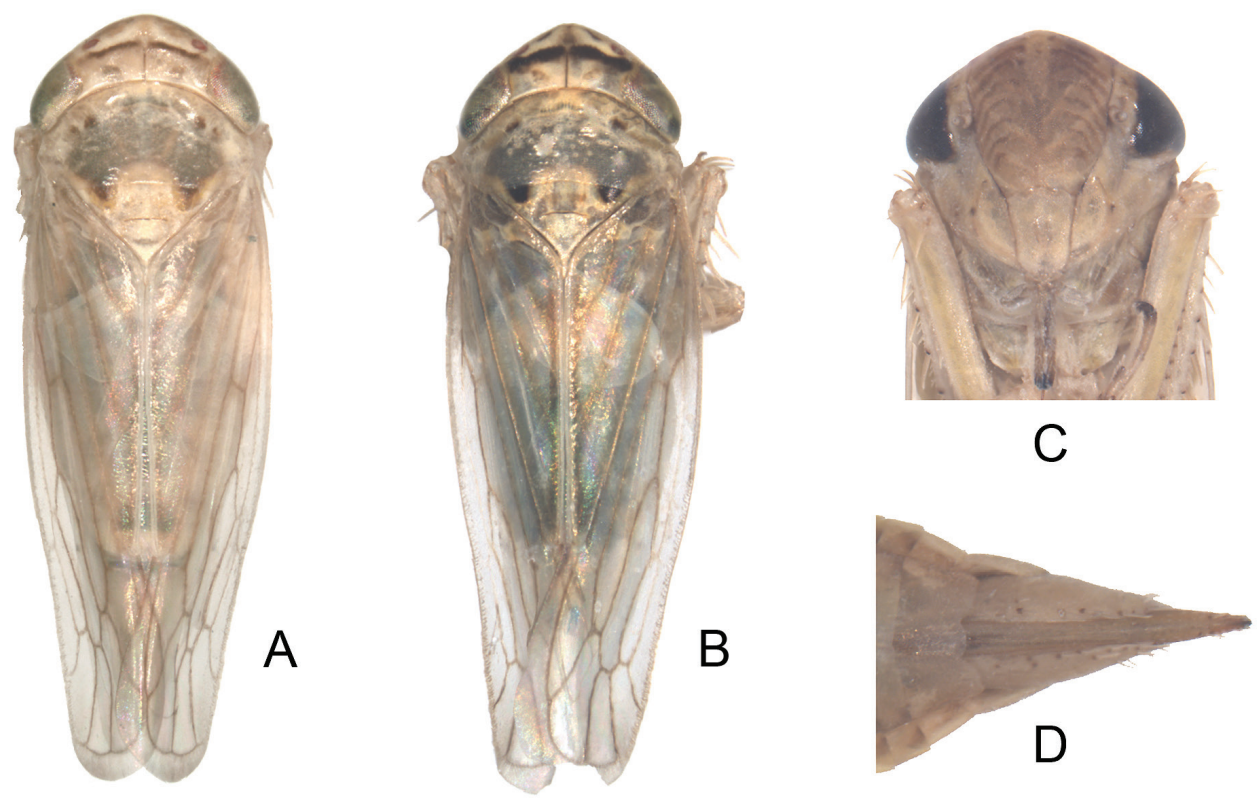

Plate I. Exitianus nanus. A-B habitus, dorsal view $\mathbf{C}$ face $\mathbf{D}$ the end of female abdomen, ventral view.

(Fig. 2A). Aedeagal shaft slightly laterally compressed with small subapical dorsal gonoduct (Fig. 2C); without processes (Figs 2B-C).

Female. Sternite VII with posterior margin tri-lobed (Plate I: D).

Material examined. China: Zhejiang Prov.: 1 female, Wuyanling, 2.VIII.2005, coll. DY; Fujian Prov.: 8 males, 15 females, Wuyishan, Nantan, 12.VIII.2002, coll. SQ; 41 males, 48 females, Guangze County, 23.VIII.2002, coll. SQ; Jiangxi Prov.: 16 males, 5 females, Anfu County, 10.VIII.2002, coll. SQ; Henan Prov.: 1 male, Baiyunshan, 17.VIII.2008, coll. LL; Hunan Prov.: 1 female, Hengshan, 30.VIII.1980, coll. TX; Guangdong Prov.: 1 male, 1 female, Shenzhen City, VIII.1986, coll. ZY; Guangxi Prov.: 1 female, Fangcheng City, 3.VI.2000, coll. Li Wenzhu (IZCAS); Hainan Prov.: 10 males, 2 females, Liangyuan, 10/29.V.1983, coll. ZY; 1 male, Wuzhishan, 640m, 16.V.2007, coll. DY; 2 males, 5 females, Jianfengling, 22.VII.2010, coll. WY; 4 males, Wuzhishan City, Maoyang Town, 3.VIII.2010, coll. Sun Jing; 3 females, Yinggeling, 4.VIII.2010, coll. WY; 30 males, 40 females, Bawangling, 9.VIII.2010, coll. WY; 7 males, 2 females, Limu, $933 \mathrm{~m}$, 22.VIII.2010, coll. WY; 61 males, 30 females, Tongguling, 26.VIII.2010, coll. WY; Yunnan Prov.: 1 male, Mengla County, Yaoqu Town, 660m, 3.V.1991, coll. Liu Guanchun \& Cai Wanzhi; 1 male, Mengla County, Yaoqu Town, 18.VI.1991, coll. WT; 2 females, Mengla County, Menglun, 19.V.1991, coll. WT; 2 males, Jinghong City, Jinghong County, 30.VIII.2010, coll. Han Juan; 1 male, Jinghong City, Jinghong County, 23.X.2010, coll. Chai Yonghui \& Feng Jinian; 1 male, Menglian County, 971m, 24.V.2011, coll. LL; 1 male, Lancang County, 25.V.2011, coll. 

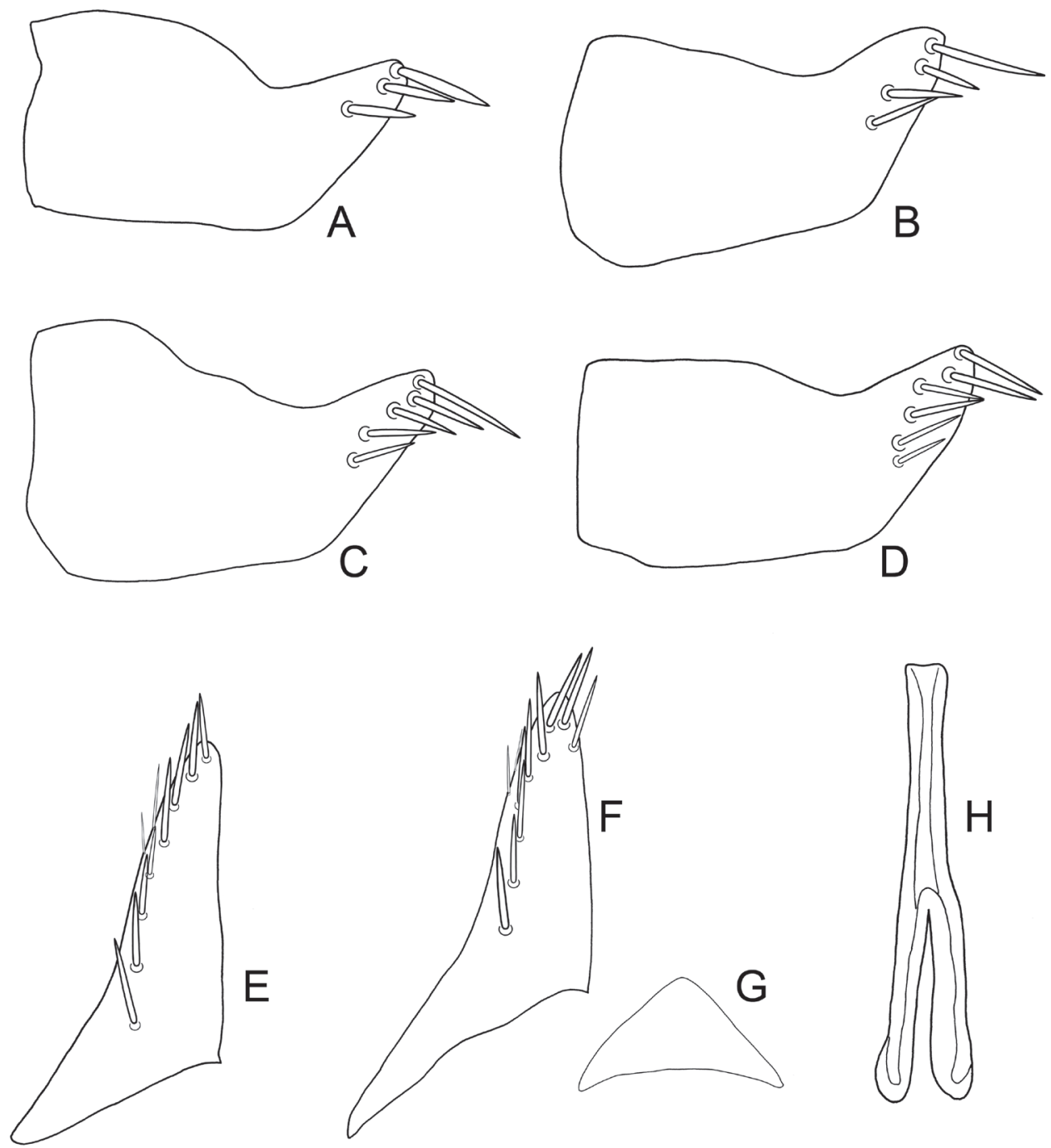

Figure I. Exitianus nanus. A-D male pygofer side, lateral view E-F subgenital plate, ventral view $\mathbf{G}$ valve, ventral view $\mathbf{H}$ connective, dorsal view.

LL; 2 males, Yexianggu, 1226m, 9.VI.2011, coll. LL; 1 male, Zhenyuan County, 13.VI.2011, coll. LL. All deposited in NWAFU, except where indicated and mainly collected at light. Abbreviations for collectors: DY: Duan Yani; SQ: Sun Qinxia; LL: Lu Lin; TX: Tong Xinwang; ZY: Zhang Yalin; WY: Wang Yang; WT: Wang Yinglun \& Tian Rungang.

Distribution. Eastern Hemisphere.

Remarks. E. fulvinervis was described by Li \& He (1993) based on specimens collected from Tibet. As these fall within the variation found in $E$. nanus, the two species are here synonymised. 

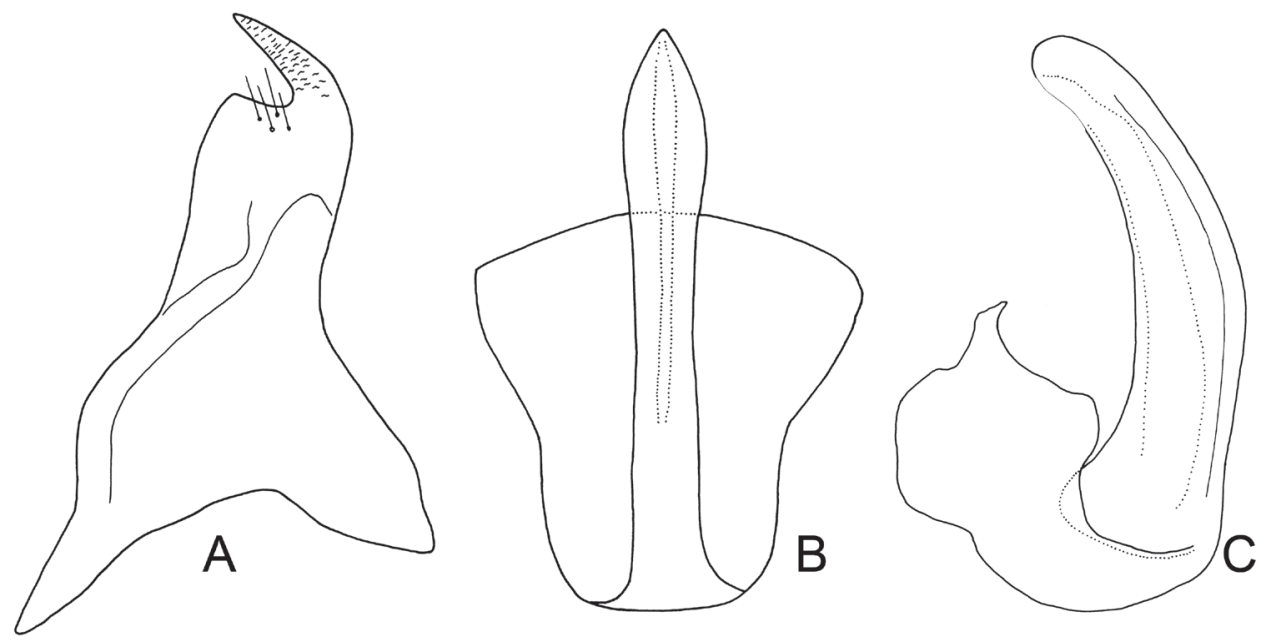

Figure 2. Exitianus nanus. A style, dorsal view B, C aedeagus, ventral and lateral view, respectively.

\section{Exitianus indicus (Distant)}

http://species-id.net/wiki/Exitianus_indicus

Plate II, Figures 3-6

Athysanus indicus Distant, 1908: 344.

Athysanus atkinsoni; Distant 1908: 345. Synonymized by Ross 1968: 12.

Exitianus indicus; Ross 1968: 12, figs 9-10, 26-30, 69.

Exitianus major; Ahmed, Qadeer and Malik 1988: 10, fig. 1. Synonymized by Khatri and Webb 2010: 10.

Description. Length. Male: $4.0-4.5 \mathrm{~mm}$; female: $4.0-5.2 \mathrm{~mm}$.

Yellow-brown with variable transverse arcuate brown band on vertex (Plate II: A-E); frontoclypeus with faint brown lateral arcs (Plate II: F). Scutellum with faint brown basal triangles (Plate II: A-E).

Male genitalia. Pygofer side usually with 2-3 apical brown or black macrosetae (Figs 3-4). Style preapical lobe narrowly triangular, apophysis abruptly tapered at apex (Fig. 5E). Aedeagal shaft strongly laterally compressed, gonopore large with rim forming concave margin in lateral view; with pair of small dorsobasal processes (Figs 5G, 6).

Female. Sternite VII with posterior margin with a shallow notch in mid-line (Plate II: G).

Material examined. China: Jilin Prov.: 1 male, Lingjiang City, 30.VII.1983, coll. Wu Zhengliang \& Hua Baozhen; Zhejiang Prov.: 21 males, 10 females, Wuyanling, 400m, 1.VIII.2005, coll. DY; Fujian Prov.: 1 male, Wuyishan, Nantan, 18.VIII.2002, coll. SQ; 2 males, Guangze County, 24.VIII.2002, coll. SQ; 1 male, Wuyishan Sanggang, 19.VII.2006, coll. YM; 41 males, 10 females, Shanghang County, Buyun Town, 21.VII.2009, coll. CY; 3 males, 1 female, Wuyishan, Tongmucun, 7.VIII.2009, coll. CY; Jiangxi Prov.: 34 males, 


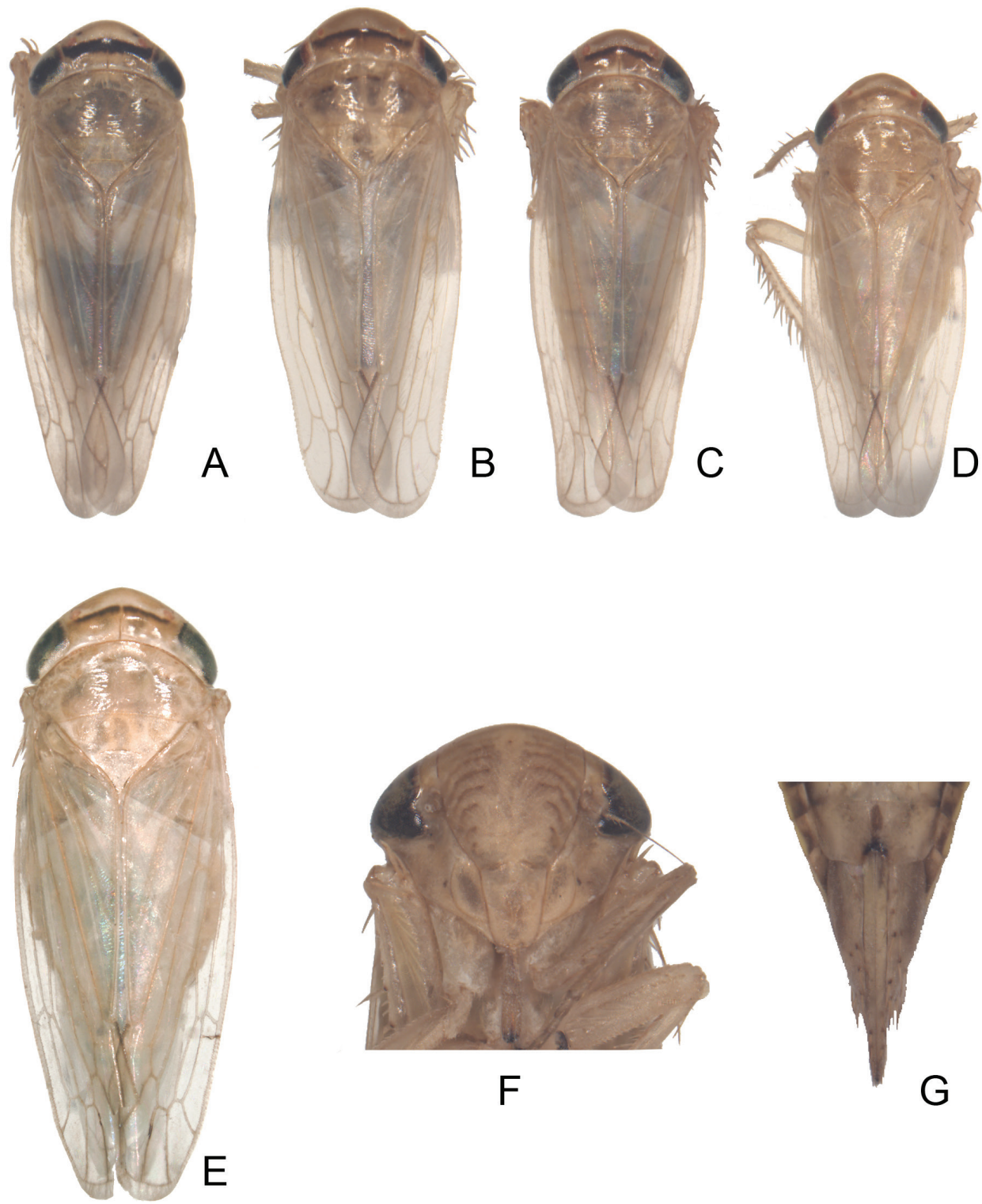

Plate II. Exitianus indicus. A-E habitus, dorsal view $\mathbf{F}$ face $\mathbf{G}$ the end of female abdomen, ventral view.

10 females, Anfu County, 10.VIII.2002; 4 males, 4 females, Ruijin City, Baying Town, 280m, 15.VIII.2004, coll. WC \& YM; 7 males, 6 females, Pingxiang City, Lianhua County, 4.VIII.2002, coll. SQ; Henan Prov.: 1 male, Jigongshan, 11.VII.1997, coll. SQ; 1 male, Ruijin City, Baying Town, 280m, 15.VIII.2004, coll. WC \& YM; 1 male, Baiyunshan, 17.VIII.2008, coll. LL; Hubei Prov.: 1 male, Wudangshan, 22.VII.2001, coll. Huang Min \& Zhang Guiling; Hunan Prov.: 1 male, Chenzhou City, 28.VIII.1985, coll. ZY \& Chai Yonghui; 9 males, 3 females, Changde City, Huanan Factory, 22.VII.2002, coll. SQ; 6 

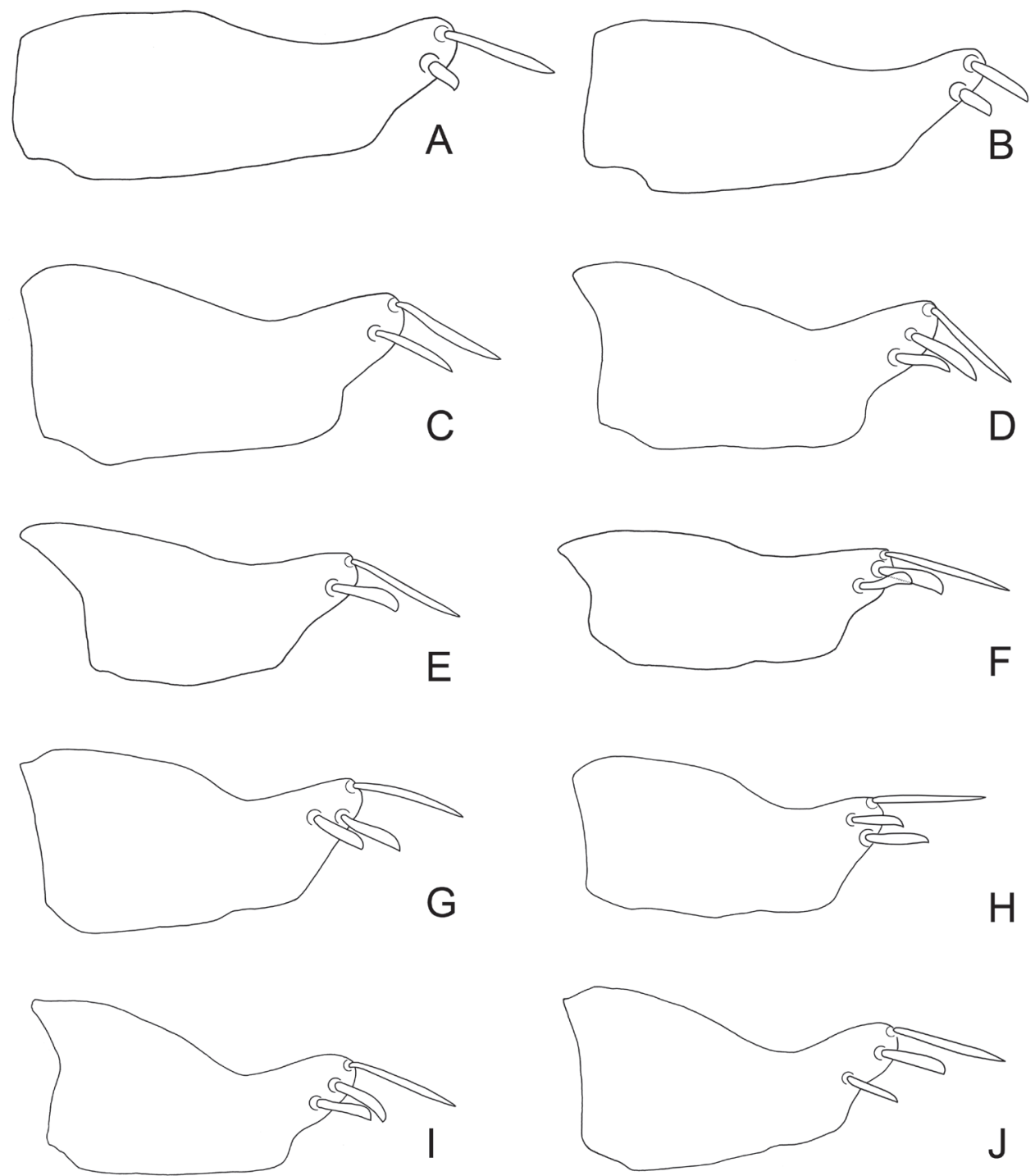

Figure 3. Exitianus indicus. A-J male pygofer side, lateral view from the same specimen, respectively.

males, Zhangjiajie, 25.VII.2002; Guangdong Prov.: 1 male, Dianbai County, 13.IV.1983, coll. ZY; 1 male, Shenzhen, 18.IV.1983, coll. ZY; 1 male, Dinghushan, 7.VII.1985, coll. ZY; Guangxi Prov.: 10 males, 4 females, Huaping, 9.VIII.2000, coll. LZ; 1 male, Huaping, 26.VIII.2000, coll. LZ; 5 males, Fangchenggang City, Naqin Town, 1-3.VIII.2001, coll. He Zhiqiang; 13 males, 6 females, Xinzhai, 18.VIII.2005, coll. YM \& KJ; 1 male, Yuanbaoshan, 12.VIII.2006, coll. YM \& KJ; Hainan Prov.: 10 males, 5 females, Yacheng, 6.V.1983, coll. ZY; 1 male, Wuzhishan, 720m, 31.VII.2009, coll. Gaoxia; 1 male, Bawangling, 9.VIII.2010, coll. WY; 1 male, Tongguling, 26.VIII.2010, coll. WY; Sichuan Prov.: 

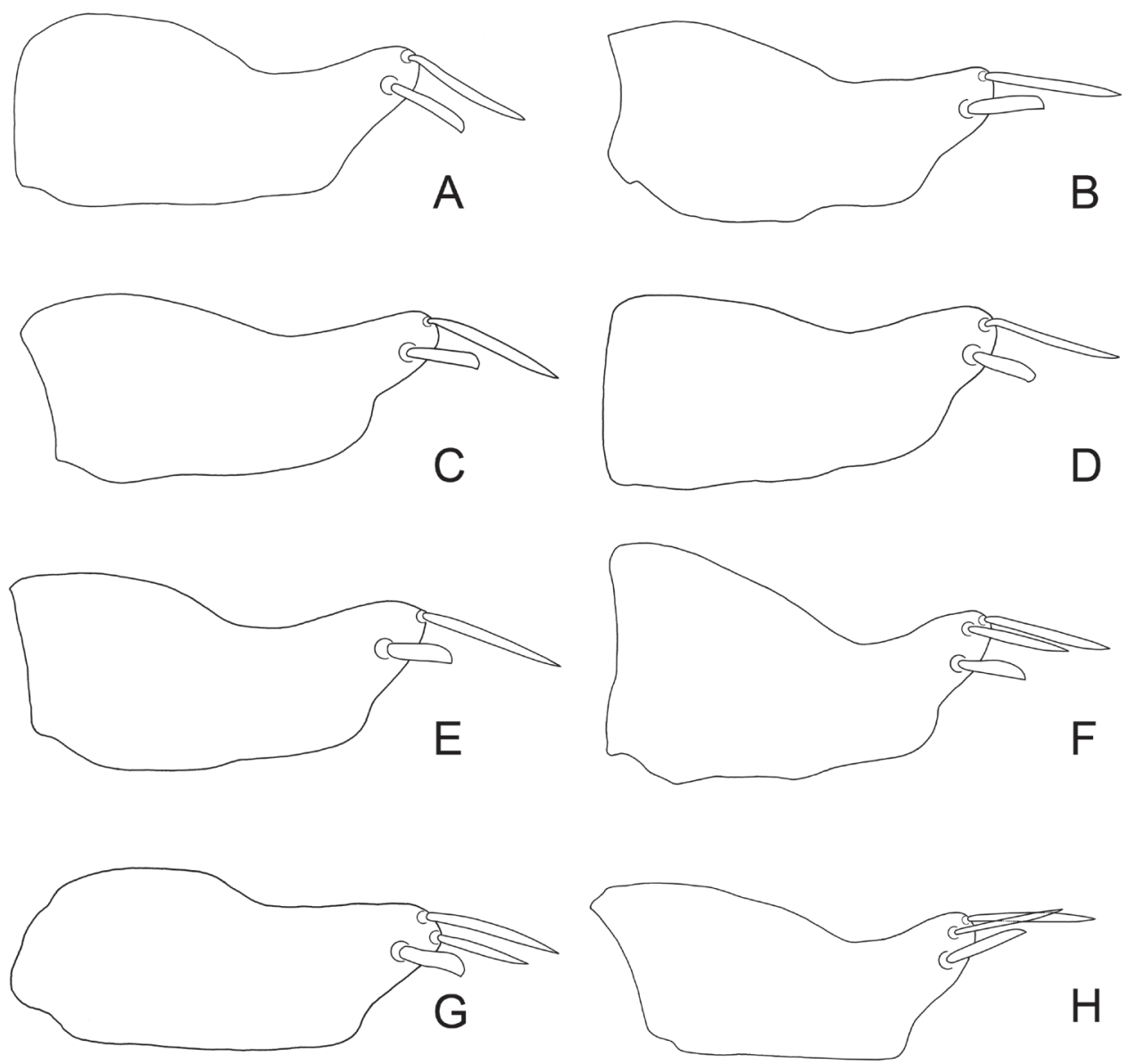

Figure 4. Exitianus indicus. A-H male pygofer side, lateral view.

2 males, 9 females, Kangding, 2500m, 8.XI.1999, coll. Qin Daozheng; 2 males, 8 females, Zhubalong, 2450m, 11.VII.2011, coll. Sun Qiang; Guizhou Prov.: 5 males, Guiyang City, Huaxi Park, 1100m, 25.VII.2001; Yunnan Prov.: 1 male, Daluo Town, 26.X.1987, coll. Feng Jinian \& Lili; 10 males, 8 females, Mengla County, Yaoqu Town, V.1991; 1 male, Tengchong County, 22.XI.1999; 2 males, Xishuangbanna, 11.VII.2003; 1 male, Mengla City, 21.VII.2005, coll. LL; 1 male, Simao City, 30.VII.2005, coll. LL; 31 males, 20 females, Tengchong County, Huoshan Park, 1930m, 14.VIII.2005, coll. YM \& KJ; 1 male, Dali, 29.VIII.2010, coll. ZM; 1 male, Diqing, 14.VIII.2010, coll. ZM; 1 male, Jinghong City, 1.IX.2010, coll. ZM; 1 male, Daluo Town, 679m, 23.V.2011, coll. LL; 1 male, Lancang County, 25.V.2011, coll. LL; 1 male, Nansan Town, 29.V.2011, coll. LL; 1 male, Yingjiang County, Zhanxi Town, 1009m, 2.VI.2011, coll. LL; 1 male, Tengchong County, 1632m, 5.VI.2011, coll. LL; 4 males, Lushui County, Chenggan Town, 1013m, 6.VI.2011, coll. LL; 1 male, Zhenyuan County, 13.VI.2011, coll. LL; Shaanxi Prov.: 1 male, Liuba County, 20.VII.1995, coll. ZR; 3 males, 3 females, Liuba County, 

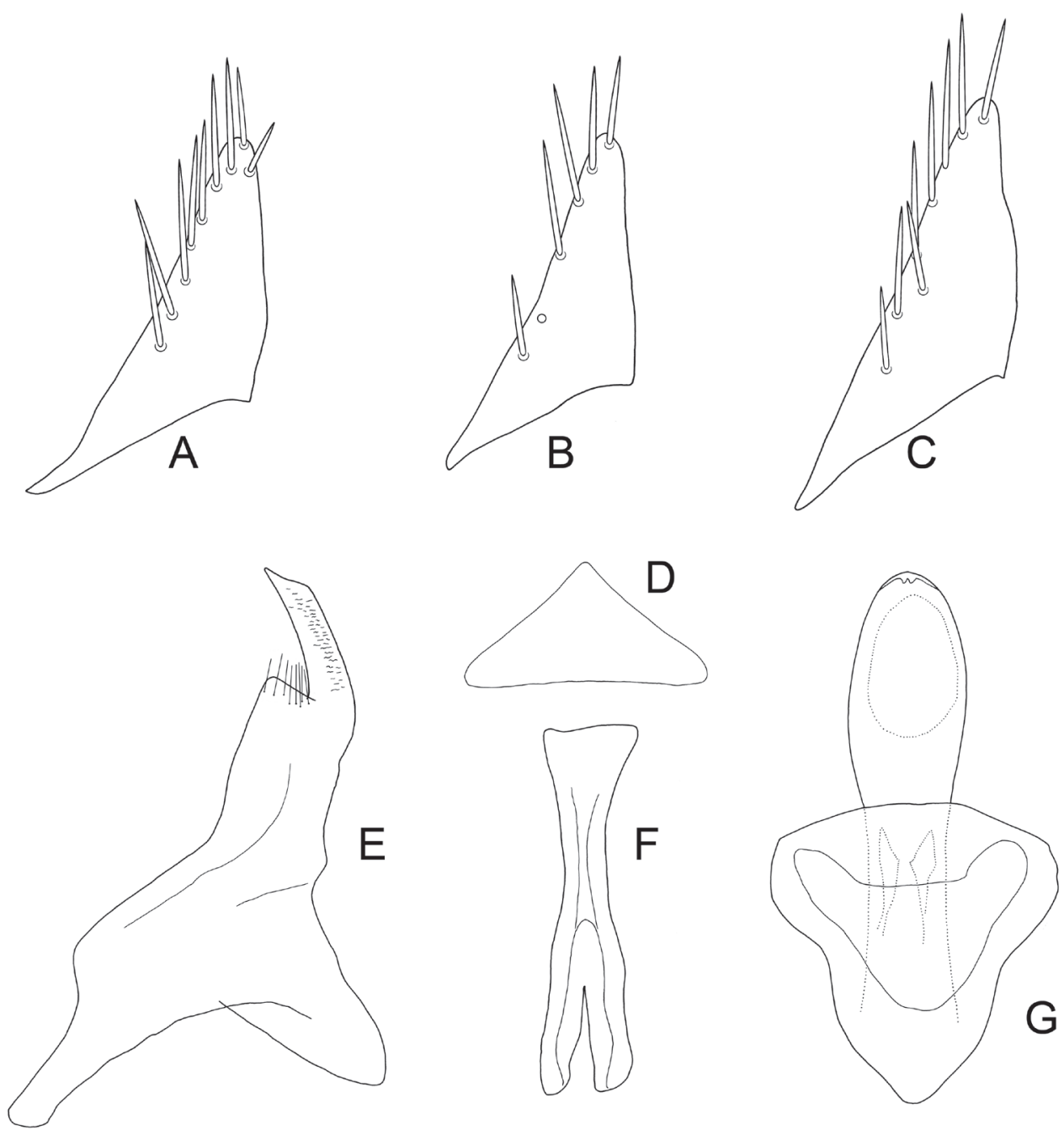

Figure 5. Exitianus indicus. A-C subgenital plate, ventral view $\mathbf{D}$ valve, ventral view $\mathbf{E}$ style, dorsal view $\mathbf{F}$ connective, dorsal view $\mathbf{G}$ aedeagus, dorsal view.

20.VIII.1995, coll. ZR; 1 male, Zhouzhi County, 24.IX.2008, coll. LL; 1 male, Foping County, 1060m, 1.X.2008, coll. LL; Gansu Prov.: 1 male, Cheng County, 25.VII.2002, coll. WC \& Shang Suqin; 1 male, Ruijin City, Baying Town, 280m, 15.VIII.2004, coll. WC \& YM. All deposited in NWAFU and mainly collected at light. Abbreviations for collectors: DY: Duan Yani; SQ: Sun Qinxia; LL: Lu Lin; YM: Yang Meixia; CY: Cao Yanghui; ZY: Zhang Yalin; ZM: Zhang Meng; ZR: Zhang Wenzhu \& Ren Liyun; WC: Wei Cong; LZ: Liu Zhenjiang; KJ: Kang Juxia; WY: Wang Yang.

Distribution. Eastern Hemisphere.

Remarks. Considerable variation was found in the apical black macrosetae of the male pygofer and shape of the aedeagus in this species (see Figs 3, $4 \& 6$ ). 

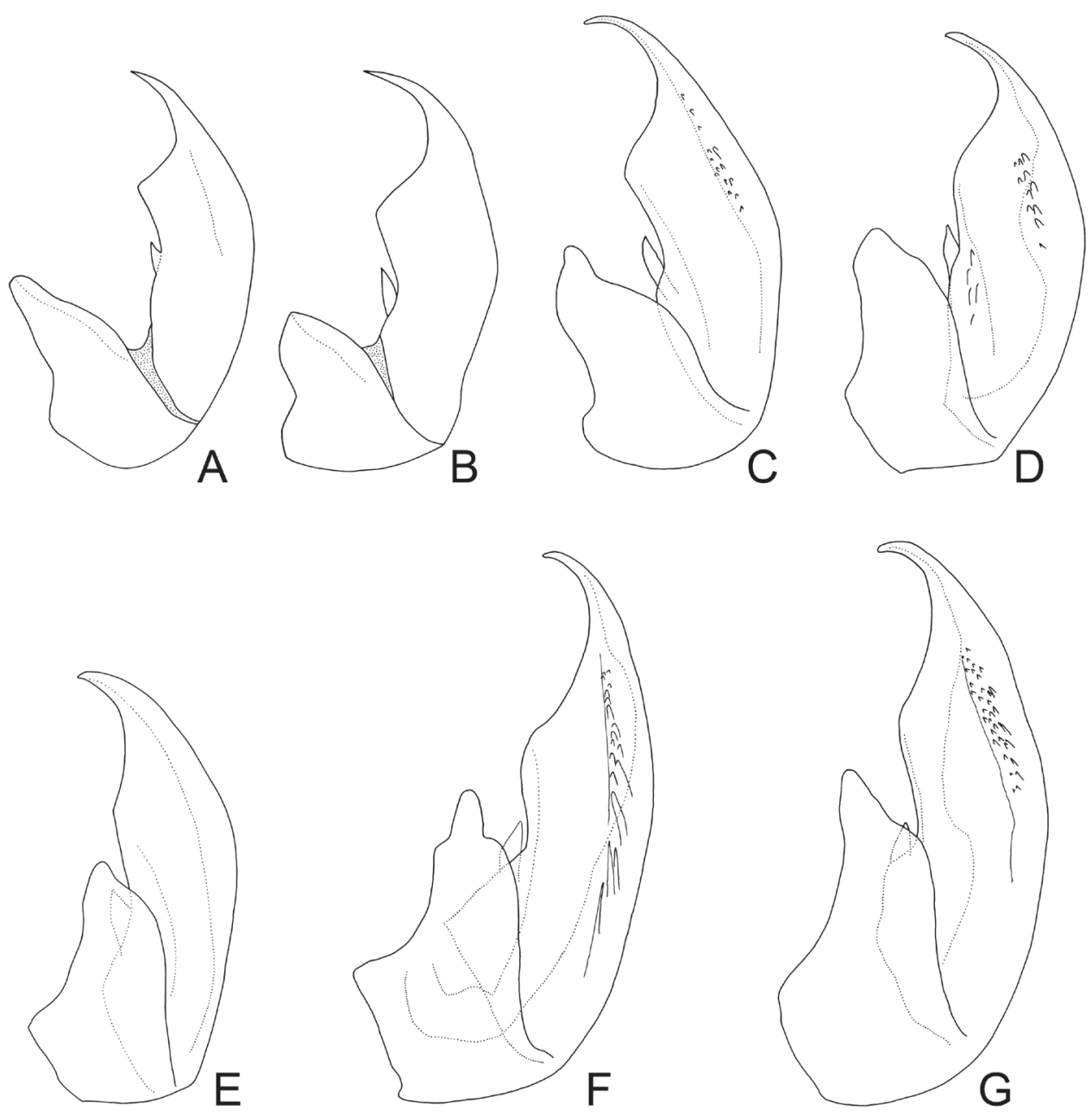

Figure 6. Exitianus indicus. A-G aedeagus, lateral view A, B (after Ross, 1968)

\section{Acknowledgements}

We express our sincere thanks to Mr. M. D. Webb, the Natural History Museum, London, UK, and Dr. C. H. Dietrich, Department of Entomology, University of Illinois, USA for reading the manuscript and making some suggestions. We thank Dr. C. A. Viraktamath, Department of Entomology, University of Agricultural Sciences, Bangalore, India, and Dr. J. N. Zahniser, Department of Entomology, University of Illinois, USA for revising the manuscript. We would like to acknowledge the Institute of Zoology, the Chinese Academy of Sciences for the loan of specimens. This research is supported by the National Natural Science Foundation of China (30970385, 31093430, 31000968) and the Fok Ying-Tong Education Foundation for Young Teachers in the Higher Education Institutions of China (131022). 


\section{References}

Ahmed M (1986) Some investigations of leafhoppers of grasslands and allied crops in Pakistan. Proceedings of Pakistan Congress of Zoology 6: 51-62.

Ahmed M, Rao S (1986) Some commonly found leaf and planthoppers on vegetable plants in the suburbs of Peshawar N.W.F.P., Pakistan. Proceedings of Pakistan Congress of Zoology 6: 73-80.

Ahmed M, Qadeer A, Malik KF (1988) Some new cicadellids from grasslands of Karachi, Pakistan (Homoptera, Cicadellidae). Great Basin Naturalist Memoirs 12: 10-17.

Ball ED (1929) A supplemental revision of the genus Athysanus in North America (Homoptera, Cicadellidae). Transactions of the American Entomological Society 55: 1-8.

Bergevin E (1925) Description d'une nouvelle espèce d'Athysanus suceur de sang humain de l'extrême Sud Algérien (Hémiptère-Homoptère Jassidae). Archives de l'Institut Pasteur d'Algérie 3: 42-44.

Distant WL (1908) Rhynchota-Homoptera. In: Bingham CT (Ed) The Fauna of British India, including Ceylon and Burma, 4, 501 pp.

Distant WL (1909) "Sealark" Rhynchota. Transactions of the Linnean Society of London, Second Series Zoology 13(1): 29-47.

Distant WL (1918) Rhynchota, Homoptera: Appendix. Heteroptera: Addenda. In: Shipley AE, Marshall AK (Eds) The Fauna of British India, including Ceylon and Burma, 7, 210 pp.

Dlabola J (1963) Typen und wenig bekannte Arten aus der Sammlung H. Haupt mit Beschreibungen einiger Zikadenarten aus Siberien (Homoptera). Acta Entomologica Musei nationalis Pragae 35: 313-331.

Dmitriev DA (2003) Larvae of leafhoppers of the subfamily Deltocephalinae (Homoptera, Cicadellidae) from European Russian and adjacent territories. II. Tribes Grypotini, Selenocephalini, Goniagnathini, Fieberiellini, Tetartostylini, Macrostelini and Doraturini. Entomologicheskoe Obozrenie 82(3): 650-686.

Emeljanov AF (1999) A key to genera of the subfamily Deltocephalinae s.l. (Homoptera, Cicadellidae) from Kazakhstan, Middle Asia, and Mongolia with description of new genera and subgenera. Entomological Review 79(5): 547-562.

Evans WJ (1947) A natural classification of leafhoppers (Jassoidea, Homoptera). Part 3. Jassidae. Transactions of the Royal Entomological Society of London 98(6): 105-271. doi: 10.1111/j.1365-2311.1947.tb01054.x

Fang Q, Black WC 4th, Blocker HD, Whitcomb RF (1993) A phylogeny of New Word Deltocephalus-like Leafhooper genera base on mitochondrial 16S ribosomal DNA sequences. Molecular Phylogenetics and Evolution 2(2): 119-131. doi: 10.1006/mpev.1993.1012

Haupt H (1927) Homoptera Palestinae I. Bulletin. The Zionist Organisation. Institute of Agriculture and Natural History. Agricultural Experiment Station Tel-Aviv Palestine 8: 5-43.

Haupt H (1930) Drei neue Homoptera-Cicadina aus Ligurien (Italien). Mitteilungen der Deutschen Entomologischen Gesellschaft 1: 153-159.

Khatri I, Webb MD (2010) The Deltocephalinae leafhoppers of Pakistan (Hemiptera, Cicadellidae). Zootaxa 2365: 1-47. 
Kirkaldy GW (1906) Leafhoppers and their natural enemies. Part IX, Leafhoppers, Hemiptera. Bulletin of the Hawaiian Sugar Planters Association Division of Entomology 1(9): 271-479. Kuoh CL (1966) Economic Insect Fauna of China. Fasc. 10, Cicadellidae. Science Press, Beijing, China, $170 \mathrm{pp}$.

Li ZZ, Dai RH, Xing JC (2011) Deltocephalinae from China (Hemiptera, Cicadellidae). Popular Science Press, Beijing, China, 359 pp.

Li ZZ, He T (1993) A new species of Exitianus from Xizang (Homoptera, Euscelinae). Journal of Guizhou Agriculture College supp. 12: 27-28.

Linnavuori RE (1959) Revision of the Neotropical Deltocephalinae and some related subfamilies (Homoptera). Annales Zoologici Societatis Zoologicae Botanicae Fennicae 'Vanamo' 20: 1-370. Linnavuori RE (1975) Homoptera: Cicadellidae, Supplement. Insects of Micronesia 6(9): 611-632. Linnavuori RE, DeLong DM (1978) Some new or little known Neotropical Deltocephalinae (Homoptera, Cicadellidae). Brenesia 14-15: 227-247.

Matsumura S (1914) Die Jassinen und einige neue Acocephalinen Japans. Journal of the College of Agriculture, Tohoku Imperial University Sapporo 5: 165-240.

McKamey SH (in press) Leafhoppers of the World Database.

Melichar L (1911) Collections recuillies par M.M. de Rothschild dans l'Afrique Orientale. Homoptères. Bulletin du Muséum National d'Histoire Naturelle, Paris, 106-117.

Metcalf ZP (1967) General catalogue of the Homoptera. Fascicle VI. Cicadelloidea. Part 10 Euscelidae Section I. Agricultural Research Service, U.S. Department of Agriculture, Washington, D.C., 1077 pp.

Motschulsky VI (1863) Essai d'un catalogue des insectes de l'ile Ceylan. Bulletin de la Société Impériale des Naturalistes de Moscou 36: 1-153.

Oman PW (1949) The Nearctic leafhoppers (Homoptera, Cicadellidae) A generic classification and check list. Memoirs of the Entomological Society of Washington 3: 1-253.

Ross HH (1968) The evolution and dispersal of the grassland leafhopper genus Exitianus, with keys to the Old World species (Cicadellidae-Hemiptera). Bulletin of the British Museum Entomology 22(1): 1-30.

Uhler PR (1880) Remarks on a new form of jassid. American Entomologist 3(3): 72-73.

Van Duzee EP (1933) The Templeton Crocker Expedition of the California Academy of Sciences, 1932, No. 4. Characters of twenty-four new species of Hemiptera from the Galapagos Islands and the coast and islands of Central America and Mexico. Proceedings of the California Academy of Sciences San Francisco Ser. 4(21): 25-40.

Zachvatkin AA (1935) Notes on the Homoptera-Cicadina of Jemen. Wissenschaftliche Berichte Moskauer Staatsuniversität 4: 106-115.

Zahniser JN (2008) Seven new species and new distributions of Old World Chiasmini (Hemiptera, Cicadellidae, Deltocephalinae), with a redescription, key to genera and species checklist for the tribe. Zootaxa 1808: 1-32.

Zahniser JN, Dietrich CH (2013) A review of the tribes of Deltocephalinae (Hemiptera: Auchenorrhyncha: Cicadellidae). European Journal of Taxonomy 45: 1-211.

Zhang YL (1990) A taxonomic study of Chinese Cicadellidae (Homoptera). Tianze Press, Yangling, Shaanxi, China, 218 pp. 